\title{
Vientos de libertad a ambas orillas del Atlántico. Las Cortes de Cádiz y la Asamblea del año XIII
}

Winds of freedom on both sides of the Atlantic. The Cadiz Cortes and the Assembly of 1813

\section{Facundo Lafit}

Docente de Historia Americana II en la Universidad Nacional de La Plata (UNLP), doctorando en el Instituto de Historia Argentina y Americana "Dr Emilio Ravignani", becario de posgrado del Consejo Nacional de Investigaciones Científicas y Técnicas (CONICET - Buenos Aires / Argentina) e-mail: lafitfacundo@gmail.com

\section{Resumo}

El presente artículo busca indagar la recepción que tuvieron en el espacio rioplatense tanto la Constitución de 1812 como la labor de las Cortes de Cádiz, en el proceso político revolucionario que desembocará en la Asamblea General Constituyente del año XIII. El enfoque que utilizaremos parte de entender a ambos procesos constituyentes enmarcados en una misma cultura constitucional hispánica, con un sustrato y lenguaje jurídico similar a ambos lados del Atlántico. Y entendemos que dicha recepción no será solo de los artículos de la Constitución sino también de la labor legislativa de las Cortes, de las discusiones que trajo aparejadas en la prensa y los tratados políticos, integrándose a otros lenguajes y modelos constitucionales que operaban en el espacio rioplatense.

\section{Abstract}

This article studies the reception of the Constitution of 1812 and the legislative work of the Cadiz Cortes in the Rio de la Plata, on the revolutionary political process, which will lead into the General Constituent Assembly of 1813.The approach used on this work begins with the understanding that both constitutional processes are framed in the same Hispanic constitutional culture, with a similar background and legal language on both sides of the Atlantic. We understand that this reception will be not only from constitutional articles but also from the legislative work of the Parliament, the related discussions in the Press, and the political treaties, joining other languages and constitutional models operating in the Rio de la Plata.

Palabras claves

Constitución de 1812- Asamblea del año XIII- Cultura constitucionalLiberalismo hispánico

Keywords

Constitution 1812- Assembly 1813- Constitutional culture- Hispanic liberalism 
1

Ver por ejemplo GONZÁLEZ, Ariosto. Las primeras fórmulas constitucionales en los países del Plata: 1810-1813. Montevidéu: Ed. Claudio García y Cía., 1941; también LEVAGGI, Abelardo. Constitución de 1812: presencia latinoamericana. In: TERRADILLOS BASOCO, J. (coord.). La

Constitución de 1812: reflexiones jurídicas en la víspera del bicentenario. Cádiz: Diputación de Cádiz, 2006.
2

El modelo de "Revoluciones Hispánicas" de Guerra ha sido cuestionado en los últimos años desde el campo de la Historia Intelectual y la Historia Conceptual. Tal es el caso de la crítica de Elias Palti, que en su libro El tiempo de la política. Lenguaje e historia en el siglo XIX, Buenos Aires: Siglo XXI, 2007, discute la interpretación de Guerra y la llamada escuela revisionista, al afirmar que, al mantener la dicotomía entre modernidad y tradición, no terminan de romper con la visión teleológica de la historia que ellos mismos critican al cuestionar los "mitos nacionalistas" de la historiografia tradicional. El autor pone énfasis en el estudio de las condiciones de enunciación de los conceptos (por ejemplo, soberanía, pacto, centralismo, nación, etc.) despojándolos del anclaje en "tipos ideales" y las visiones dicotómicas tan comunes a la Historia de las Ideas tradicional. Roberto Breña plantea una crítica similar a la tesis de Guerra, argumentando la imposibilidad de encontrar "estados puros" tanto del liberalismo como del absolutismo a nivel iberoamericano, prefiriendo utilizar la diada "reformismo-tradicionalismo" para analizar el pensamiento español de ese periodo. El autor investiga en profundidad las relaciones entre los liberales peninsulares y americanos, llegando a la conclusión de la fuerte homogeneidad ideológica entre ambos producto de la importante difusión del liberalismo español gracias al surgimiento de la prensa. BREÑA, Roberto, El primer liberalismo español y la emancipación de América: tradición y reforma. Revista de Estudios Políticos (Nueva Época), $\mathrm{n}$. 121, 2003.
La Constitución Española de 1812 logró trascender el acotado marco en el que fue promulgada, una ciudad sitiada por el ejército más poderoso de su época, e irradiar el espectro del constitucionalismo en las décadas siguientes. Al momento de ser sancionada el 19 de marzo de 1812, los virreinatos americanos ya habian comenzado con el sinuoso recorrido que terminaría desembocando en su emancipación. A pesar de esto, fue jurada en varios territorios que mantenian aún sus vínculos con la metrópoli. Sabemos que su impacto en dichas regiones leales fue capital, pero conocemos poco de sus efectos en aquellas que, como el Rio de la Plata -con excepción de Montevideo que se encontraba en manos realistas-, no la juraron ni adoptaron. Desde el campo de la historia del derecho se han realizado algunos estudios que han destacado las "deudas gaditanas" en las primeras legislaciones rioplatenses, pero aún no se ha profundizado en otros aspectos más allá de lo estrictamente jurídico. ${ }^{1}$

El presente trabajo busca indagar la recepción que tuvieron en el espacio rioplatense tanto la Constitución de 1812 como la labor de las Cortes de Cádiz, en el proceso político revolucionario que desembocará en la Asamblea General Constituyente del año XIII. Está enmarcado en un estudio más amplio sobre la cultura política rioplatense en el tránsito entre el antiguo régimen y la república, donde se analiza la relación entre el sector radical de la dirigencia revolucionaria rioplatense y el liberalismo hispánico a partir del proceso de politización abierto con la crisis de 1808. Partimos de considerar a la revolución liberal peninsular y a las emancipatorias americanas como parte de un mismo proceso dialécticamente imbricado de ruptura con el antiguo régimen y el absolutismo. Movimiento que tuvo su epicentro en la Península, y más precisamente en el Cádiz de las Cortes, pero atravesó al conjunto del imperio hispánico. En este marco son destacables ciertas caracteristicas comunes de la elite dirigente y letrada hispanoamericana en la adopción de las "ideas modernas". Adopción definida por importantes mutaciones ideológicas relacionadas a las alteraciones ocurridas en el plano de las prácticas políticas, ambas como resultado de la emergencia de nuevos sujetos políticos y ámbitos de sociabilidad. Como han planteado FrançoisXavier Guerra y más recientemente Roberto Breña, debemos observar con atención la difusión del reformismo ilustrado en primer término, y del primer liberalismo español en América, principalmente a partir de la crisis de 1808, cuando el movimiento juntista eclosiona en la península y extiende sus repercusiones hacia los territorios de ultramar. ${ }^{2}$ Pero esta impronta peninsular sobre el pensamiento político americano comenzará a resquebrajarse ante la intransigencia de la metrópoli hacia los reclamos y aspiraciones americanas, fundamentalmente en relación a la igualdad de representación, la descentralización política y la liberalización comercial.

El enfoque que utilizaremos en este trabajo parte de entender a ambos procesos constituyentes enmarcados en una misma cultura constitucional hispánica, con un sustrato y lenguaje jurídico similar a ambos lados del Atlántico. Desde esta perspectiva, se buscará demostrar que existen suficientes indicios para afirmar que, a pesar de no haber sido jurada, la Constitución de Cádiz tuvo una significativa recepción en el marco de los proyectos constituyentes que se comenzaron a discutir en el espacio rioplatense, en particular en el primer intento serio de organizar a las Provincias Unidas, como fue la Asamblea del año XIII. Y que dicha recepción no será solo de los artículos de la Constitución sino también de la labor legislativa de las Cortes, de las discusiones que trajo aparejadas en 
Véase FERNÁNDEZ SARASOLA, Ignacio. La Constitución española de 1812 y su proyección europea e iberoamericana. Revista Fundamentos, Oviedo: Junta General del Principado de Asturias, n. 2, 2000.

\section{4}

Esta corriente alcanzó su cénit en las obras de los ilustrados Francisco Martínez Marina y Gaspar de Jovellanos. Algunos historiadores consideran que fue utilizada por el liberalismo revolucionario con el objetivo de legitimar, en base a una supuesta tradición, los cambios que traía aparejada la Constitución de 1812 y ocultar de esta manera el parentesco de aquellos con la legislación francesa. Véase, por ejemplo, BREÑA, Roberto. El primer liberalismo español y los procesos de emancipación de América, 18081824. Una revisión historiográfica del liberalismo hispánico. México: El Colegio de México, 2006.

5

PORTILLO VALDÉS, José Maria. La constitución en el atlántico hispano, 1808-1824. Revista Fundamentos, Oviedo: Junta General del Principado de Asturias, n. 6, 2010, p. 123-178. la prensa y los tratados políticos, integrándose a otros lenguajes y modelos constitucionales que operaban en el espacio rioplatense. Vínculos muchas veces omitidos por encontrarse en guerra con la metrópoli, al igual que fue enmascarado el influjo del pensamiento francés en las Cortes doceañistas por similares razones.

\section{La Constitución de 1812: fuentes y aportes originales}

El 19 de marzo de 1812 la Constitución era proclamada por las Cortes extraordinarias en medio de un clima de algarabía popular. Surgía como respuesta a la profunda crisis en la que se encontraba la monarquía española a partir de las abdicaciones de Bayona y la invasión francesa, fundamentalmente como producto genuino del proceso revolucionario que tenía como eje a la península, pero que atravesaba todo el Imperio. El parlamentarismo español nacía con diputados no sólo peninsulares: pensada como marco jurídico por el conjunto de la monarquía a ambos márgenes del Atlántico, fueron participes en su elaboración representantes de los distintos territorios americanos, aunque designados generalmente de manera arbitraria. Existe cierto consenso historiográfico en considerar que, a pesar del variopinto componente ideológico de las Cortes, el texto constitucional resultante reflejó en gran medida el ideario de la tendencia liberal (Podemos diferenciar al menos cuatro grupos: realistas absolutistas, realistas constitucionalistas, liberales y la diputación americana que, más allá de su heterogeneidad doctrinaria funcionaban en muchos casos como grupo en torno a las reivindicaciones del Nuevo Mundo). ${ }^{3}$ Esta afirmación no niega el hecho de que la Constitución de 1812, a pesar del predominio liberal, fue fruto de una negociación con los sectores moderados y conservadores que poseian una nada despreciable representación en las Cortes extraordinarias. Aun así significó una clara ruptura con el Antiguo Régimen, fundamentalmente en dos de sus principios medulares: la soberanía nacional y la división de poderes.

Mucho se ha discutido sobre la originalidad y las deudas de la constitución gaditana en relación a otros modelos constitucionales. A grandes rasgos, la paternidad liberal de este texto la dotó de significativos vínculos con las Constitución francesa, fundamentalmente con la de 1791 y, en menor grado, con la de 1793. El grupo liberal encontraba en el pensamiento revolucionario francés las herramientas para llevar adelante los cambios radicales que ambicionaban para la sociedad española. Sin embargo, y teniéndose en cuenta esta filiación expresada en su concepción racional normativa, la comprensión de los derechos como naturales y su fundamentación en la soberanía nacional, la Constitución de 1812 presentaba importantes rasgos originales, entre ellos, una lógica argumentativa que se destaca como uno de sus elementos más distintivos: hablamos del fuerte historicismo nacionalista del que está impregnado prácticamente todo el texto gaditano. ${ }^{4}$

Entre 1808 y 1824 ningún otro espacio se mostró tan proclive a la experimentación constitucional como el que constituia la monarquía española. ${ }^{5}$ Los signos de "modernidad" que poblaron este período son elocuentes: constituciones, declaraciones, publicaciones, procesos electorales, etc. Se pueden rastrear algunos antecedentes de lo que podemos denominar como cultura constitucional hispánica hacia las décadas finales del siglo XVIII. Son varios los letrados que a esa altura empezaban a reflexionar en base a la necesidad de una Constitución como reaseguro de respeto de los 
6

lbidem.

7

Con respecto a la Diputación permanente, habia existido bajo los Habsburgo un organismo con esa misma denominación. Su función era la de monitorear que se cumplieran las disposiciones de la Hacienda pactadas con el rey después de la conclusión de la reunión de las Cortes, pero en general se caracterizaban por estar cooptada por la monarquía. Los liberales en su afán historicista, revistieron con el mismo nombre al nuevo cuerpo, pero a diferencia del anterior, buscaban realmente que ejerciera un control y limitación al rey.

8

FERNÁNDEZ SARASOLA, Ignacio, 0p. cit., p. 23.

9

En ocasión de las celebraciones del bicentenario de su promulgación, son muchos los títulos publicados que abordan el problema específico del impacto de la carta doceañista en los territorios americanos, entre ellos: CHUST CALERO, Manuel (coord.). 1812, El poder de la palabra, América y la Constitución de 1812. Madri: AC/E, 2012; BONILLA, Heraclio (ed.). La constitución de 1812 en Hispanoamérica y España. Bogotá: Universidad Nacional de Colombia, 2012. Véase también el dossier dirigido por LORENTE, Marta. La Constitución de 1812: miradas y perspectivas. Teoria y Derecho. Revista de pensamiento jurídico, n. 10, 2011. derechos individuales y como mecanismo de equilibrio de poderes. Textos de Victorian de Villalba o Valentín de Foronda iban en ese camino, discusiones que no se limitaban sólo a la Península sino que también se daban en el Nuevo Mundo.

La originalidad del texto gaditano, también se puede observar en relación al tratamiento de lo religioso donde se establece, a diferencia de otros textos constitucionales, la confesionalidad del Estado y la intolerancia hacia otros cultos que no sea el católico. Los textos y la cultura constitucional hispánica en general están impregnados de una fuerte carga de catolicismo. Se ha querido ver en el artículo referente a la religión de la Constitución de 1812 una concesión liberal a los conservadores, pero creemos que éste tiene que ver, en realidad, con un aspecto muy esencial y consecuente de la cultura del primer constitucionalismo hispánico. ${ }^{6}$

Por otro lado, en referencia a la cuestión de los poderes, se creaban dos organismos que tenian como objetivo controlar la acción del monarca: la Diputación permanente y el Consejo de Estado, ambos originales del doceañismo. ${ }^{7}$ Este último, de composición parcialmente estamental, sirvió como remedo de la cámara alta exigida por el realismo, muy afín al parlamentarismo británico, pero que terminó derrotado imponiéndose el formato unicameral de los liberales. Otra característica sobresaliente es la ausencia de una declaración de derechos, distanciándose de esta manera, y creemos conscientemente, del modelo francés. Aquéllos aparecen a lo largo del articulado y en función siempre de limitaciones a los poderes ejecutivo y judicial. ${ }^{8}$

\section{Proyección gaditana en lberoamérica}

La Constitución de 1812, promulgada en el marco de una Cádiz asediada por el ejército napoleónico, logró a la postre vencer las particularidades de su nacimiento, y transcender e irradiar al constitucionalismo europeo e iberoamericano en la siguiente década. No sólo fue traducida a varios idiomas, sino que tuvo una importante recepción en aquellos paises que no poseían una tradición constitucionalista, como lo eran Portugal e Italia, donde ganó el apoyo y fue difundida por los grupos liberales y progresistas. A pesar de estar emparentada con las francesas, contaba con la ventaja de ser más moderada que éstas y no traer consigo el estigma de haber desembocado en el llamado "período de terror".

El primer impacto de la "Pepa" -como se la conocía popularmente a la Constitución gaditana- en Hispanoamérica, es precisamente el de encauzar a sus provincias a las experiencias constitucionales. La Constitución es jurada y puesta en práctica, no sin resistencia como se sabe, en aquellas regiones que aún permanecian leales, pero también circula y deja su huella en los territorios insurgentes. Entre los efectos directos sobre las provincias que la aplicaron, sucintamente podemos destacar: 1) una importante porción de la población es incluida en la categoría de ciudadano -con excepción de los afroamericanos- $y_{1}$ en términos formales, es beneficiaria de una ampliación de derechos civiles; 2 ) a partir de los procesos electorales que comienzan a desarrollarse se experimenta una novedosa movilización política de la población, fundamentalmente en las zonas urbanas; 3) se introducen nuevos órganos político-administrativos como los ayuntamientos constitucionales y las diputaciones provinciales. ${ }^{9}$ La cultura política y formación intelectual de las elites americanas no se distanció mucho de la de sus pares peninsulares, formando ambas parte de un amplio escenario de 
10

PORTILLO VALDÉS, José María. Op. cit.

En 1810 el Deán Funes explicaba que sólo mediante medida de tipo constitucional, de reformulación del pacto, podia imaginarse una reconstrucción de la cadena monárquica española. Gaceta extraordinaria, 7 de agosto de 1810. Mariano Moreno, unos meses más tarde planteaba que: "Seria preferible una asamblea general que reúna la representación de todos los pueblos libres de la Monarquia, y que una vez vuelto el Rey ocupara nuevamente su trono con las variaciones y reformas que los pueblos hubiesen establecido. Pero la perfidia de las autoridades de las capitales, más las grandes distancias y falta de comunicación entre las regiones, vuelven una tarea imposible cumplir con ese objetivo." Gazeta de Buenos Aires, 6 de diciembre de 1810. Esta última cita no debe confundirnos y llevarnos a alinear a Moreno entre aquellos que consideraban una opción la recomposición del Imperio, y menos a esta altura de los acontecimientos; pero sí debemos tomar nota que hace referencia a un debate que circulaba entre las élites dirigentes americanas.

12

Para profundizar sobre estos temas véase TíO VALLEJO, Gabriela. Rupturas precoces y legalidades provisorias. El fin del poder español en el Rio de la Plata. Revista Ayer, n. 74, 2009, p. 133-162.

13

Ver algunos de estos argumentos en MORENO Mariano. Sobre las miras del Congreso que acaba de convocarse y la Constitución del Estado. Doctrina democrática, edición de Ricardo Rojas, Buenos Aires: Libreria "La Facultad", 1915, p. 237-238.

TERNAVASIO, Marcela. Gobernar la revolución: poderes en disputa en el Río de la Plata, 18101816. Buenos Aires: Siglo XXI Editores, 2007, p. 57. profundas transformaciones interconectadas. Una vinculación estrechada en gran medida por un elemento hasta ese momento inédito en el mundo hispánico: el surgimiento de una nueva prensa libre y crítica que proliferó en la península y que tuvo una importante difusión en América.

Entre 1810 y 1824 se consolidó una cultura constitucional en el Atlántico hispánico, con una fuerte raíz en el derecho de gentes, particularmente en relación al problema de la soberanía nacional. Los españoles peninsulares encontraron en la constitución una herramienta viable para la resistencia a la invasión francesa y al intento de mediatización que Napoleón ambicionaba para la monarquía católica. En América, el paso de las juntas a los congresos constituyentes también coincidió con el momento en que fue necesario afirmarse como un cuerpo independiente de la metrópoli. Aun así debe decirse que hasta el regreso de Fernando VII, la respuesta constitucional fue pensada por muchos para el conjunto del espacio hispánico. ${ }^{10}$ Existía cierta idea de que mediante una Constitución se podía recomponer un cuerpo político provincial y, a partir de ahi, intentar otra del cuerpo general de la monarquia."

La mixtura de elementos neoescolásticos que el texto gaditano conllevaba -que a América habían llegado de la mano de jesuitas como Suarez, Vitoria y Mariana- con la filosofía iusnaturalista, significó una sencilla asimilación por parte de las élites ilustradas americanas, aventajando de esa forma a otros modelos como el británico y el francés. En ese sentido, una de las claves que permitió esta aceptación de la Constitución en las regiones realistas, como así también potenciar su recepción en los territorios insurgentes, fue que su concepción de la ciudadanía estaba ligada a la tradicional categoria de vecino. Los ciudadanos eran el conjunto de individuos bautizados, reconocidos y reconocibles del cuerpo de la Iglesia, pertenecientes a la comunidad parroquial. Los alcaldes de barrio y los curas continuaban siendo capitales para acreditar la condición de vecindad. La nación española era entendida, de esta manera, como la reunión de vecinos padres de familia que se organizaban en pueblos o provincias. ${ }^{12}$

Las primeras fórmulas constitucionales y legislaciones americanas también apelaron al pasado, a la justificación histórica, para legitimarse. En sus reivindicaciones ante la metrópoli, recurrieron a las antiguas Leyes de Indias y a la concepción de la monarquía plural de los Austrias. La perspectiva historicista recorrió desde la apelación al pacto subjectionis hasta la justificación de la ruptura, condenando la conquista y realzando algunos aspectos del pasado prehispánico. ${ }^{13}$

En palabras de Marcela Ternavasio:

La necesidad de pasar de una etapa juntista a otra constituyente en Cádiz fue producto de la precariedad de las juntas y de la necesidad de legitimar en un nuevo sujeto de imputación soberana - la nación española- el poder asumido de manera provisional por aquellos cuerpos (...) Lo ocurrido en América fue similar, sumado al hecho nada sencillo de que cada comunidad debía adoptar una posición frente a las Cortes peninsulares y decidir si se integraba en esa nueva soberanía transatlántica. ${ }^{14}$

Las provincias del Río de la Plata, aun no habiendo vivido, como sabemos, el "experimento de Cádiz" como otras regiones del imperio colonial español, inició igualmente de manera muy temprana un período constitucional marcado por la elaboración de reglamentos, estatutos y proyectos de Constitución, que intentaron ordenar lo que a la postre fue un derrotero bastante sinuoso durante toda la primera mitad del siglo XIX. 
Al respecto, véase la obra clásica de ARTOLA, Miguel. Los orígenes de la España contemporánea. Madrid: IEP, 1959.
Es acusado el secretario de la Junta Central, Manuel Quintana, por el ocultamiento del decreto. En sus memorias se defendia de esta manera: "Las Cortes, pues, fueron reunidas bajo una representación única y nacional, no por la supuesta ocultación del decreto, sino porque los votos de los dos Consejos, la opinión públicamente decididamente declarada en este sentido y la situación de las cosas así lo prescribian", QUINTANA, Manuel. Memoria sobre el proceso y prisión de Don Manuel José Quintana en 1814. Alicante: Biblioteca Virtual Miguel de Cervantes, 1999, p. 199.
Los escabrosos caminos para llegar a una Asamblea Constituyente en ambas orillas del Atlántico.

Aunque en 1808 en la Península era casi unánime la demanda de una convocatoria a las Cortes, la realidad implicaba que éstas no eran entendidas de la misma manera por los distintos sectores que pugnaban en el marco de la crisis monárquica. Los absolutistas pensaban en aquella institución estructurada por los Austrias, a la que los Borbones habian mantenido en el olvido, unas Cortes estamentales y limitadas únicamente a elegir una nueva regencia. En cambio, los liberales propugnaban obtener unas nuevas Cortes racionalmente organizadas y con la fundamental misión de promulgar una Constitución y llevar adelante un proceso de transformaciones profundas que sepultaran el Antiguo Régimen. Jovellanos, principal referente del sector moderado y hombre fuerte de la Junta Central, a pesar de ver en la coyuntura la posibilidad de que se plasmaran las reformas ilustradas por las que venía batallando toda una vida, en numerosas circunstancias se posicionó en la vereda de enfrente del liberalismo, defendiendo el carácter estamental y tradicional de las Cortes e impugnando la necesidad de una nueva Constitución para la monarquía.

En junio de 1809 se conforma la Comisión de Cortes de la Junta Central. Como primera medida se convoca a la llamada "Consulta al pais", donde se piden informes y proyectos de reforma a distintas instituciones y personalidades del reino, en relación a la futura labor de las Cortes. Consistía en un cuestionario con cuatro preguntas claves, pero finalmente muchas de las respuestas terminarian siendo proyectos constitucionales. La llegada de informes a partir de julio supera ampliamente la capacidad de la Junta Central para poder procesarlos. ${ }^{15}$

En el marco de los trastornos en la situación militar y política sucedidos a fines de 1809 y principios del año siguiente, desaparece la Junta de legislación sin que ésta pueda cumplir su principal tarea, la redacción de un proyecto constitucional, lo que provocará que sean las mismas Cortes las creadoras del código y, por lo tanto, que éste se encuentre más influenciado por las tendencias revolucionarias. El 1 de enero de 1810 se dicta una circular de la Junta Central convocando a las ciudades con voto a Cortes y a las juntas, a elegir los diputados que habian de representarlas. Llamativamente no son puestas en circulación las que corresponden a los obispos y grandes del reino. Jovellanos sigue insistiendo con el formato estamental y bicameral, logrando finalmente su cometido. La última acción de la Junta Central antes de su disolución será un extenso articulado dirigido a la Regencia donde se pautan los puntos de la convocatoria para las Cortes, el famoso y controvertido decreto del 29 de enero de 1810, estableciendo los atributos tradicionales.

El Consejo de Regencia, de impronta más conservadora que la Junta, se caracterizará por una actitud puramente dilatoria. Recién en junio empezará a implementar las instrucciones realizadas por esta última. Misteriosamente, el decreto del 29 de enero de 1810 desaparece, mientras que los diputados que ya han llegado a Cádiz presionan para que no sea tomado en cuenta. ${ }^{16}$ El Consejo de Estado, ante el clima adverso que se vive en la ciudad sitiada con respecto a una representación de tipo tradicional, finalmente define la composición única y no estamental, a sólo un mes de que sean inauguradas las sesiones.

Del otro lado del Atlántico, la idea de una convocatoria a un congreso constituyente en el Rio de la Plata tuvo sus primeras formulaciones en 
En la serie de artículos que publica en la Gazeta de Buenos Aires bajo el título "Sobre las miras del Congreso que acaba de convocarse y la Constitución del Estado", citado anteriormente, Moreno insiste recurrentemente en la necesidad del dictado de una constitución para las provincias del sur : "Nuestros representantes van a tratar sobre la suerte de unos pueblos que desean ser felices, pero que no podrán serlo, hasta que un código de leyes sabias establezca la honestidad de las costumbres, la seguridad de las personas, la conservación de sus derechos, los deberes del magistrado, las obligaciones del súbdito y los límites de la obediencia" Entiende que las Leyes de Indias no podian considerarse como dicho código, por carecer de principios de razón, reglar el comercio sobre base ruinosa del monopolio, entre otros aspectos. El Secretario de la Primera Junta considera que el americano es un teatro propicio como pocos para formar una constitución, caracterizando a las americanas como "poblaciones regulares y civilizadas" donde "la suavidad de nuestras costumbres anuncian la docilidad con que recibiremos la constitución que publiquen nuestros representantes; libres de enemigos exteriores, sofocada por la energia de la Junta la semilla de las disensiones interiores, nada hay que pueda perturbar la libertad y sosiego de los electores..." Gazeta de Buenos Aires, 1 y 6 de noviembre de 1810 .

18

Gazeta extraordinaria de Buenos Aires, 28 de febrero de 1811.

19

HALPERÍN DONGHI, Tulio. Revolución y guerra. Formación de una elite dirigente en la Argentina criolla. Buenos Aires: Siglo XXI, 1972.

20

Sobre la reconfiguración del sector más radical de la dirigencia porteña se puede consultar MOLINA, Eugenia. Las modernas prácticas asociativas como ámbitos de definición de lazos y objetivos políticos durante el proceso revolucionario (1810-1820). Universum, n. 16, 2001, p. 407-437.

21

"Oración inaugural. Pronunciada en la apertura de la Sociedad Patriótica la tarde del 13 de enero de 1812". MONTEAGUDO, Bernardo de. Escritos politicos. Buenos Aires: La Cultura Argentina, 1916.

22

"Deliberaciones y documentos producidos en la Sociedad patriótica relativos a la reunión de una Asamblea, a la declaración de la independencia y a la sanción de una constitución". En RAVIGNANI Emilio. Asambleas Constituyentes Argentinas, t. 6. Buenos Aires: Instituto de Investigaciones Históricas, Universidad de Buenos Aires, 1937-39, p.738-739.

23

Extraordinaria Ministerial, 22/oct/1812. los escritos del secretario de la Primera Junta, el joven abogado Mariano Moreno. ${ }^{17}$ Serán sus seguidores quienes, ya en la oposición al Primer Triunvirato, insistirán en la necesidad de una Constitución para el antiguo virreinato, imputándole al gobierno falta de voluntad para avanzar en ese camino. La facción dirigente, como reacción a estas críticas, cuestionará desde la prensa a las Cortes gaditanas, utilizando argumentos que buscaban deslegitimar las asambleas de tipo constituyente, combinando de alguna manera en una misma táctica, los frentes interno y externo. ${ }^{18}$ La expulsión de diputados de la Junta Conservadora en diciembre de 1811 acusados de conspiración, responde a esta estrategia del Primer Triunvirato que busca detentar en solitario la autoridad sobre las provincias rioplatenses.

Hacia fines de 1812, el Río de la Plata y Chile eran los únicos territorios americanos que no habian vuelto a manos de la reacción realista. $Y$ aun en estas condiciones continentales adversas, la revolución rioplatense renovará sus bríos cuando un sector de la elite dirigente recupere el control del Estado, derrocando al Primer Triunvirato en la decisiva jornada del 8 de octubre de ese año. La Sociedad Patriótica y la Logia Lautaro, ya ambas en franco proceso de fusión, buscaron encarrilar nuevamente el proceso hacia los objetivos libertarios e hispanoamericanos iniciales, proclamándose como la continuación genuina de la tradición revolucionaria morenista. ${ }^{19}$ La llegada de Bernardo de Monteagudo a la capital, reorganizando a los desperdigados miembros del Club de Marco y convirtiéndose en el "ego conductor" de la Sociedad Patriótica, más el desembarco de los oficiales San Martín, Zapiola y Alvear, y con ellos de la Logia Lautaro en América, habian dinamizado a la corriente más revolucionaria del proceso. ${ }^{20}$ Desde diciembre de 1811, cuando Monteagudo se sumó como redactor de la Gazeta, la Sociedad Patriótica y la Logia Lautaro estaban socavando la autoridad del Primer Triunvirato, cuestionando su falta de voluntad política para la convocatoria a un congreso constituyente mientras abogaban por la urgente declaración de la independencia. En la "Oración inaugural" de la Sociedad Patriótica, Monteagudo proclamaba que:

\begin{abstract}
...la soberanía reside sólo en el pueblo y la autoridad en las leyes: ella debe sostener que la voluntad general es la única fuente de donde emana la sanción de ésta y el poder de los magistrados: debe demostrar que la majestad del pueblo es imprescriptible, inalienable y esencial por su naturaleza...21
\end{abstract}

El 21 de octubre de 1812 el nuevo gobierno dicta un decreto convocando a una Asamblea General Constituyente. Al día siguiente de los hechos del 8 de octubre, la Sociedad Patriótica había impulsado que ésta tuviera el carácter de un legislativo permanente. ${ }^{22}$ En una emisión extraordinaria de la Gazeta Ministerial, es publicado un artículo donde se relatan los acontecimientos y razones del levantamiento, y se argumenta a favor de la pronta reunión de la Asamblea.

Una asamblea general con toda la plenitud y legalidad que permitan las circunstancias, y a la que concurran los representantes de los pueblos con la extensión de poderes que quieran darles; es sin duda el mejor arbitrio para augurar la salud de la patria. Su primer objeto debe ser poner límites a la obediencia del pueblo, estableciendo la garantía de sus derechos, y fijando el sistema que debe regir a las provincias unidas, cuya indefinición no puede absolutamente justificarse, ni por las dificultades de la empresa, ni por los peligros que nos rodean. ${ }^{23}$ 
24

"Convocando a elecciones para diputados a la Asamblea general", Buenos Aires, 24/oct/1812, Registro Nacional, p. 185.

25

Sobre este punto, véase DE GORI, Esteban. Autogobierno y revolución. Lenguaje político de las élites dirigentes de Buenos Aires. Politeia, UCV, n. 43, 2009

26

La Junta había enviado varios comunicados a las Cortes no reconociendo la representatividad de los diputados suplentes por Buenos Aires elegidos en Cádiz: Francisco López Lisperguer, Luis Velazco y Manuel Rodríguez. CHUST CALERO, Manuel. La cuestión nacional americana en las Cortes de Cádiz. Valencia: UNED-UNAM, 1998.

27

Mariano Moreno, "Sobre las miras del Congreso que acaba de convocarse y la Constitución del Estado", Gazeta de Buenos Aires, 13/nov/1810.

28

Para el autor es la revolución española la que provoca un período de iniciación democrática en el Río de la Plata inmediato a la Revolución de Mayo con el llamado a elección de un diputado vocal a la Junta Central. A su vez, entenderá que prácticamente todas las declaraciones y leyes más importantes de la Asamblea del año XIII son una glosa de iguales actos consumados por las Cortes de Cádiz. Muchos de sus planteos se entienden por el contexto en el que escribió esta obra y su afinidad política con la causa republicana en plena Guerra Civil Española. GONZÁLEZ, Julio V. Filiación histórica del gobierno representativo argentino. Buenos Aires: La vanguardia, 1937.

29

LEVAGGI, Abelardo. Op. Cit., p. 77.
El 30 de ese mismo mes se expedía por la declaración de la independencia de manera absoluta. Ya en el manifiesto que acompañaba al reglamento para la convocatoria al congreso constituyente se advertía que "el eterno cautiverio del Señor Fernando VII ha hecho desaparecer sus últimos derechos".24 La decisión de avanzar hacia un proceso constitucional buscaba, a fin de cuentas, sustituir al Rey y a la propia Monarquía por un corpus normativo que estabilizara y legitimara al nuevo poder soberano, aun cuando la independencia absoluta no contaba todavía con un consenso mayoritario. ${ }^{25}$

\section{La Asamblea del año XIII y la impronta gaditana}

La Asamblea se inaugura en el marco de un clima de gran expectativa. El 31 de enero se produce el juramento de los diputados, invocando la soberanía nacional como había sucedido en Cádiz, y es acompañado por desfiles de tropas, fiestas nocturnas y adornos en la Plaza de la Victoria y el Cabildo. Ese mismo día dicta un decreto cuyo primer artículo declara "que reside en ella la representación y el ejercicio de la soberanía de las Provincias Unidas del Rio de la Plata", y al determinar que debian promulgarse sus decisiones suprime la frase "a nombre de Fernando VII", lo cual va prefigurando el decidido propósito de encaminar sus pasos hacia la declaración de la independencia. Este rumbo rupturista al que se orienta el Río de la Plata, que en ningún momento ha reconocido a las Cortes de Cádiz ni a la Constitución emanada de ella, no implicaba que el texto constitucional o la legislación gaditana no formaran parte del repertorio de fuentes que permitieran pensar posibles recorridos constitucionales. ${ }^{26}$ Haber puesto en tela de juicio la legitimidad de las Cortes cuestionando la desigualdad de representación, como se observa en el "Discurso sobre la nulidad de las Cortes" publicado en la Gazeta del 25 de febrero de 1811, no impedía que se compartieran muchas de las ideas que habian inspirado sus leyes. Un ideario que, como hemos dicho, era producto de una cultura política y constitucional común en el mundo hispánico. Mariano Moreno no deja lugar a dudas sobre esta cuestión cuando decía a fines de 1810:

\footnotetext{
Como las necesidades de los pueblos y los derechos que han reasumido por el estado político del Reino, son la verdadera medida de lo que deben y pueden sus representantes, creí oportuno recordar la conducta de los pueblos de España en igual situación a la nuestra. Sus pasos no serán la única guía de los nuestros, pues en lo que no fueron rectos, recurriremos a aquellos principios eternos de razón y justicia, origen puro y primitivo de todo derecho; sin embargo, en todo lo que obraron con acierto, creo una ventaja preferir su ejemplo a la sencilla proposición de un publicista, porque a la fuerza del convencimiento se agregará la confusión de nuestros contrarios, cuando se consideren empeñados en nuestro exterminio, sin otro delito que pretender lo mismo que los pueblos de España obraron legítimamente. ${ }^{27}$
}

La recepción de determinados textos jurídicos y constitucionales la podemos rastrear con anterioridad a la labor de la Asamblea. Sin compartir la tesis de Julio V. González, que ve al conjunto del movimiento revolucionario rioplatense como herencia directa de la revolución peninsular, son destacables algunos puntos de contacto entre ambos procesos..$^{28} \mathrm{ES}$ importante tener en cuenta que desde fines de 1811 circuló en el espacio rioplatense el "Proyecto de Constitución Política de la Monarquía Española presentado a las Cortes Generales y extraordinarias por su Comisión de Constitución", impreso en Cádiz en forma de folleto. ${ }^{29}$ En la reglamentación 
Véase al respecto GOLDMAN, Noemi. Libertad de imprenta, opinión pública y debate constitucional en el Rio de la Plata (1810-1827). Prismas, Revista de historia intelectual, n. 4, 2000, p. 9-20.

31

"Reglamento de Policia Interior", reproducido en SILVA, Carlos A. Poder Legislativo de la Nación Argentina. Buenos Aires: Cámara de Diputados de la Nación, t. I, 1937, p. 74-77.

32

El Grito del Sud, 20/oct/1812.

33

El resto de la comisión estaba compuesta por Juan Larrea, Francisco José Planes, Tomás Valle, Antonio Sáenz y el doctor Dongo, en calidad de secretario. El Grito del Sud, 10/nov/1812.

34

La comisión estaba integrada en este caso por Valentín Gómez, Manuel José Garcia, José Agrelo, Pedro Somellera, Nicolás Herrera, Hipólito Vieytes y Gervasio Antonio de Posadas. Gazeta Ministerial del gobierno de Buenos Aires, 13/nov/1812.

35

GONZÁLEZ, Ariosto. Las primeras fórmulas constitucionales en los paises del Plata: 1810-1813. Montevidéu: Ed. Claudio García y Cía., 1941.

36

Con una partición destacada desde la misma Revolución de Mayo, Cardoso se vinculó hacia el año 1811 con el sector morenista formando parte activa de la Sociedad Patriótica y el movimiento del 8 de octubre. Con el ascenso de esta fracción al poder, Cardoso se irá distanciando debido al cambio que este grupo experimenta hacia una posición cada vez más centralista con respecto al poder político. Su militancia a favor del proyecto federal de Artigas lo posicionará ya a comienzos de 1813 como un elemento disidente para el gobierno porteño, al punto que se ordena su detención por fuerzas de seguridad en julio de ese año. Entre los papeles que se le secuestran de su domicilio se encuentran las constituciones de Estados Unidos, la de Venezuela y la española de 1812. HERRERO, Fabián. Fragmentos para armar. Indicios sobre la presencia artiguista en Buenos Aires. Revista de Indias, vol. LXX, n. 250, 2010, p. 623-650.

37

Proyecto de Constitución para las provincias del Rio de la Plata, formado por una comisión especial nombrada en 1812. In RAVIGNANI, Emilio. Op. Cit. t. 6, p. 607-616 sobre libertad de imprenta de abril de 1811 dictada por la Junta Grande por iniciativa del Deán Funes se percibe ya cierta ascendencia gaditana. ${ }^{30}$ Como así también en el reglamento de división de poderes de octubre del mismo año, muy similar al reglamento provisional del poder ejecutivo sancionado por las Cortes en enero de 1811. En relación a sus formas, el Primer Triunvirato no distaba mucho del Consejo de Regencia que tanto rechazo había generado en el Río de la Plata. Pero es en el período hegemonizado por la Asamblea General Constituyente y fundamentalmente en los proyectos constitucionales que fueron encargados por este cuerpo donde podemos observar la sombra de la Carta Magna doceañista con mayor intensidad. El mismo Reglamento de Policía Interior, único documento normativo de la Asamblea a falta de un estatuto propio, fue copiado casi textualmente del sancionado por las Cortes extraordinarias. ${ }^{31}$

Desde El Grito del Sud, periódico que hacía las veces de órgano oficial de la Sociedad Patriótica, se insistía recurrentemente en la necesidad de ilustrar al pueblo como condición sine qua non para avanzar en el camino constituyente $y_{1}$ en ese sentido, se planteaba la importancia de la divulgación y discusión de modelos constitucionales vinculados de alguna manera a la realidad rioplatense:

\footnotetext{
Es por lo tanto deseable, que a la mayor brevedad al pueblo se le den cuando menos nociones nada equívocas, y de una manera sencilla y la más inteligible, de los derechos que le son imprescriptible. Sería también muy bueno se publicasen impresas las constituciones de los Estados unidos de Norte América: las que ha formado la nación Venezolana, y las que han hecho célebres y felices a otras repúblicas, en lo antiguo y en lo moderno. Hasta ahora no se le ha presentado para que se ilustre, sino el pacto social de Juan Jacobo Rousseau. Esta obra por excelente y aun magistral que sea, contiene muchas ideas abstractas, que el pueblo es casi imposible que llegue a comprenderlas [...] no estamos ciertos si las bellas reglas que da el autor teóricamente, tienen la misma belleza en la práctica... ${ }^{32}$
}

En noviembre de 1812 el nuevo triunvirato se dirigió a la Sociedad Patriótica a fin de pedirle que estudiara aspectos relacionados con la administración del Estado. Para ello fue designada una comisión encabezada por su presidente Monteagudo. ${ }^{33} \mathrm{~A}$ su vez, el ejecutivo nombró una comisión oficial con el objetivo de elaborar un proyecto de código político que sirviera de base para las deliberaciones de la Asamblea. ${ }^{34}$ Finalmente, ambos terminarán redactando proyectos constitucionales. ${ }^{35}$ Se le suman a estos dos documentos, otro que se considera como el proyecto propio de la asamblea, y un cuarto atribuido al diputado artiguista Felipe Santiago Cardoso, de impronta federalista y con varios puntos de contacto con el constitucionalismo norteamericano. ${ }^{36}$

El proyecto redactado por la Comisión oficial es el que mayores vínculos presenta con la Constitución de 1812. Consta de 263 artículos clasificados en 22 capítulos. En el primero establece que las Provincias Unidas del Río de la Plata forman una república libre e independiente, que "la soberanía del Estado reside esencialmente en el pueblo" y que "el pueblo es la reunión de todos los hombres libres de la república". ${ }^{37}$ En materia religiosa, al igual que la mayoria de las legislaciones sobre este tema en todo el mundo hispánico, el proyecto coincide con lo acordado por los diputados gaditanos al disponer que la religión del Estado sea la católica (cap. III, art. 1), pero se distancia de aquélla al consignar que "ningún habitante de la república puede ser perseguido ni molestado en su persona y bienes por 
"Proyecto de Constitución para las Provincias Unidas del Rio de la Plata en la América del Sud". In: RAVIGNANI, Emilio, Op. Cit., t. 6, p. 616-633.

39

Estos planteos ya los podemos encontrar en un artículo atribuido a Monteagudo en la Gazeta de Buenos Aires del 15 y 28 de febrero de 1812: "Todos los que no tengan derecho a ser ciudadanos deben dividirse en dos clases: extranjeros y simples domiciliados. Aquellos son los que no han nacido en el territorio de las provincias unidas: estos los originarios de ellas que por su estado civil o accidental están excluidos del rango de ciudadanos. Unos y otros deben ser considerados como hombres: su derecho es igual a los oficios de humanidad, aunque no gocen de las distinciones que dispensa la patria a sus hijos predilectos."

40

El Redactor de la Asamblea, In: RAVIGNANI, Emilio. Op. Cit., t. I, p. 16-17. opiniones religiosas" (art. 3). En relación a las disposiciones del proyecto con respecto a la ciudadanía y el régimen electoral, se perciben varios puntos de contacto con la Constitución española al organizar, al igual que lo establecido en la metrópoli, un sistema electoral de tercer grado.

El proyecto elaborado por la Sociedad Patriótica se destaca, en cambio, por la riqueza de fuentes que maneja y, fundamentalmente, por ser el más original de los presentados a consideración de la Asamblea Constituyente. ${ }^{38}$ Fiel exponente del pensamiento del grupo revolucionario, el texto proclama la independencia de las Provincias Unidas, y a diferencia del proyecto de la comisión oficial, dedica dos capítulos a la declaración de los derechos individuales, emparentándose con las declaraciones francesas y distanciándose de esa manera del modelo español, que como hemos dicho los incluye a lo largo de todo el articulado. En este mismo sentido, el proyecto si hace referencia al derecho a la igualdad omitido por las Cortes, y deja claramente establecido que "todo hombre gozará de estos derechos en la Provincias Unidas sea americano o extranjero, sea ciudadano o no".39 Determina también que "la religión católica es y será siempre la del Estado", y aunque establece la tolerancia religiosa, se acerca más al texto doceañista al enfatizar la protección que el Estado le brindará al culto católico, imponiendo similar castigo al que atentara contra él como si lo hiciera contra la misma Constitución. Con respecto a la división y forma de los poderes, el proyecto de la Sociedad pareciera estar inspirado en los textos constitucionales norteamericanos y en la Declaración venezolana. Debe destacarse la propuesta de ejecutivo de carácter unipersonal, planteo que tenía a Monteagudo como principal impulsor desde sus tiempos de redactor de la Gazeta y que finalmente terminará imponiéndose en el cuerpo constituyente.

\section{Dividir y concentrar el poder}

En relación a la labor orgánica de la Asamblea, a pesar de no haber dictado Constitución alguna, estableció por medio de leyes una organización rudimentaria de los poderes públicos, determinando su funcionamiento y fijándole límites al Estado. El 27 de febrero de 1813 el congreso aprueba el "Estatuto dado al poder ejecutivo", en el que se reglamentan sus atribuciones. Se mantiene la estructura colegiada de tres miembros y se le adjudica la tarea de "ejecutar las leyes y decretos soberanos" y de "gobernar al Estado"; mientras que la Asamblea se reserva la atribución de nombrar, enjuiciar y remover a cualquiera de sus miembros. El Estatuto se presentó públicamente en El Redactor de la Asamblea, periódico a cargo de Monteagudo que, como solía hacer con lo tratado en cada sesión, acompañó la crónica con unas consideraciones sobre la división de poderes. Comenzaba diciendo: "la misma libertad conduce al despotismo y se convierte en un germen de anarquía y desolación, cuando los tres poderes que dirigen el cuerpo social se confunden en el ejercicio de sus atribuciones". Más adelante agrega: "la Asamblea General faltaría por lo mismo a sus primeros deberes, si después de haber constituido el Supremo Poder Ejecutivo lo dejase fluctuar en la perplejidad de sus atributos, exponiendo a tocar los límites del abuso, ó proceder en deliberaciones con una lentitud incierta". ${ }^{40}$ Como nos sugiere Marcela Ternavasio en su trabajo ya mencionado, a pesar de que la Asamblea se esmera en exhibir su supremacía sobre el ejecutivo, las funciones asignadas y la actividad concreta de este último no parecieron ser tan despreciables. El Triunvirato continuaba siendo un verdadero centro de poder que acaparaba en su órbita la mayoría de los asuntos de importancia. En 
41

Gazeta de Buenos Aires, 07/mar/1811.

42

TERNAVASIO, Marcela. Op. Cit.

43

Reforma del Estatuto Provisorio del Supremo

Gobierno In RAVIGNANI, Emilio. Op. cit., t. I, p. 83.

44

"¿Qué expediente deberá tomar la asamblea para dar energía al sistema, prevenir su decadencia y acelerar su perfección? La necesidad es urgentísima, el conflicto extraordinario y la salud pública es la única ley que debe consultarse: el voto de los pueblos está ya expresado de un modo terminante y solemne: su existencia y libertad son el blanco de sus deseos: todo lo que sea conforme a estos objetos, está antes de ahora sancionado por su consentimiento: últimamente, ninguna reforma parcial y precaria podrá salvarnos, sino se rectifican las bases de nuestra organización política. Yo no encuentro sino dos arbitrios para conciliar estas miras: declarar la independencia y soberanía de las provincias unidas o nombrar un dictador que responda de nuestra libertad, obrando con la plenitud de poder que elijan las circunstancias y sin más restricción que la que convenga al principal interés." Mártir o Libre, 29/set/1812.

45

Gazeta Ministerial del Gobierno de Buenos Aires, 02/fev/1814. este sentido el caso rioplatense se aleja bastante del modelo gaditano de clara supremacía del legislativo, y es posible inferir que esta situación se debió a la afinidad política entre los protagonistas de ambos poderes en el Río de la Plata. La Sociedad Patriótica y la Logia habían logrado colonizar los principales cargos del Estado revolucionario. Pero también es importante destacar que ya desde marzo de 1811 al conocerse en Buenos Aires el decreto de las Cortes sobre división de poderes del 28 de octubre de 1810, la prensa porteña había criticado la intervención "abusiva" del legislativo en los asuntos de gobierno:

Las Cortes han ocupado el lugar de la soberanía nacional erigida para el ejercicio de la voluntad general, y ya sentada en el carro del gobierno, y usando del Poder ejecutivo (...) Si sus funciones son las de primer orden, no puede ejercer las del segundo, pues el poder ejecutivo con el legislativo no pueden juntarse, sin exponer el cuerpo político, a ser presa de la violencia contra la cual fue instituido".41

Meses después, cuando el contexto se volvió más adverso a la revolución, con las derrotas de Belgrano en Vilcapugio y Ayohuma, la llegada de refuerzos a Montevideo, el conflicto ya del todo abierto con el artiguismo luego del rechazo a los diputados orientales, y las preocupantes novedades sobre los éxitos conseguidos por la resistencia española a la ocupación francesa, la dirigencia rioplatense tenderá a una mayor concentración del poder ejecutivo. ${ }^{42}$ La Asamblea General le otorgará no solo facultades extraordinarias, sino que terminará decidiendo el reemplazo del Triunvirato por una autoridad unipersonal: el Directorio..$^{43}$ La idea de un dictador pluripotenciario, como hemos dicho, ya venía siendo publicitada por Monteagudo desde marzo de 1812 en su periódico Mártir o Libre. ${ }^{44}$ Pero como el mismo Alvear reconoció en sus "Narraciones", fue extremadamente difícil convencer a los diputados debido a la animadversión que existía en la Asamblea de concentrar el poder en una sola persona. La elite dirigente recurrió a la Constitución norteamericana de 1787 y su régimen presidencialista a fin de legitimar el nuevo rumbo tomado. Junto a la creación del Director Supremo, la reforma del Estatuto dispuso la conformación del Consejo de Estado, de similares caracteristicas al establecido por el proyecto de Constitución de la comisión oficial, inspirado como hemos dicho en la Constitución española de 1812. Finalmente, la Asamblea se fue convirtiendo en un agente legitimador del ejecutivo, perdiendo sus originales funciones de equilibrar y evitar sus potenciales excesos. Unos dias después de la reforma se podía leer en la Gazeta Ministerial: "esta grande y necesaria medida, acaso habría sido mortal para el estado, si ella no fuese dictada por un poder legislativo preexistente, y si no tuviese el sello de un consentimiento que casi se confunde con la aclamación universal del Pueblo".45

\section{Soberanías en disputa}

La cuestión de la soberanía fue otro de los puntos que generó mayor conflictividad en las precoces Provincias Unidas del Río de la Plata. A pocas semanas de la instalación de la Asamblea, su presidente Carlos María de Alvear propuso una moción que definiera que "los diputados de las Provincias Unidas, lo son de la nación en general, sin perder por esto la denominación del pueblo al que deben su nombramiento, no pudiendo en ningún modo obrar en comisión". En el comentario sobre la sesión, El Redactor de la Asamblea decía: 
46

El Redactor de la Asamblea. In: RAVIGNANI, Emilio. Op. cit., t. I, p. 20-21.

47

Gazeta Ministerial del Gobierno de Buenos Aires 18/nov/1812.

48

Gazeta de Buenos Aires, 28/fev/1811.

49

CHIARAMONTE, Juan Carlos. La cuestión de la soberania en la génesis y constitución del estado argentino. Historia Constitucional (revista electrónica), n. 2, 2001. www. historiaconstitucional.com

50

GOLDMAN, Noemi. Crisis del sistema institucional colonial y desconocimiento de las Cortes de Cádiz en el Río de la Plata. In: CHUST CALERO, Manuel (coord.). La eclosión juntera. México: Fondo de Cultura Económica, 2007.

51

Fabián Herrero considera, y compartimos esa apreciación, que existen igualmente significativas diferencias entre las "Instrucciones" y el "proyecto federal" de Cardoso. Las primeras se encuentran en línea a un modelo de tipo confederal, mientras que el proyecto constitucional plantea una organización con caracteristicas de "estado federal", con mayores atribuciones al poder nacional. Como bien razona Herrero, "es probable que esta segunda constitución federalista haya sido pensada como una alternativa en una instancia de negociación con los sectores centralistas porteños, ya que responde a las condiciones políticas de la época". HERRERO, Fabián. Op. cit., p. 645. ...es indudable que por este principio es puramente hipotética la contradicción del interés parcial de un pueblo con el común de la Nación, resulta sin embargo que en el concurso de ambos, este debe prevalecer, determinando en su favor la voluntad particular de cada diputado considerado distributivamente. ${ }^{46}$

De esta manera la Asamblea, al subordinar a los "pueblos" al novedoso principio de la soberanía nacional, seguía los pasos de la Asamblea $\mathrm{Na-}$ cional francesa y de las Cortes de Cádiz. Monteagudo y sus pares parecian olvidar las fuertes críticas lanzadas desde la prensa al congreso peninsular, cuando se habian referido a las "escandalosas doctrinas de soberanía nacional" y denunciaban el espíritu autoritario y centralista de las Cortes. Al conocerse la sanción de la Constitución española la dirigencia porteña decía en noviembre de 1812:

\begin{abstract}
Estas doctrinas que tan escandalosas eran al común de los pueblos, hoy las vemos erigidas en dogma político y publicadas como leyes fundamentales de su gobierno. Ya todos saben que el único origen de toda autoridad pública es la voluntad de los pueblos....No se ignora que nadie representa a una Nación, sino los diputados que cada pueblo haya nombrado libremente, y en número proporcional a su población; y que estos diputados no tienen más poder que el que le hayan dado sus representados. ${ }^{47}$
\end{abstract}

Los mismos que habian esgrimido el principio de la fragmentación y retroversión de la soberanía a los "pueblos" para oponerse a las autoridades peninsulares y legitimar su planteo autonomista, hoy entendian perjudicial a los intereses de la nación el "mandato imperativo" de los diputados. La elección de la suplencia en Cádiz habia sido criticada en su momento por la prensa porteña justamente desde la concepción contraria:

\footnotetext{
...los miembros que deben componerlas [a las Cortes] han de ser todos procuradores nombrados por los pueblos, y llevar consigo los poderes que les hubiesen otorgados, porque son las únicas credenciales con que son reconocidos, incorporados y admitidos a deliberar en los negocios que tratasen. ${ }^{48}$
}

Como observamos nuevamente, más allá de ciertas convicciones doctrinarias que indudablemente poseían, la dirigencia revolucionaria resignificaba y adecuaba su discurso a las necesidades políticas de la coyuntura, recurriendo a aquellos conceptos y sentidos que fueran útiles a la causa última. En momentos cuando se hacía urgente la consolidación del estado nacional, en situación de guerra abierta contra la antigua metrópoli, era fundamental la unidad bajo una sola cabeza, y para la dirigencia porteña esa era la antigua sede administrativa del virreinato. ${ }^{49}$ Este afán centralista, que se volvió dominante en la primera década bajo la concepción de una "soberanía única", va a encontrar igualmente fuertes resistencias expresadas en el marco de la Asamblea por el artiguismo y sus proposiciones de tipo confederal..$^{50} \mathrm{El}$ rechazo de la diputación oriental por parte de la facción dominante responde a este conflicto que, con el correr de los meses, se irá agudizando hasta implicar el enfrentamiento en el plano militar. Las "Instrucciones" traídas por los diputados de la Banda Oriental postulaban un sistema confederal para las Provincias Unidas, presentando algunos lineamientos similares al proyecto de Constitución presentado por el diputado Felipe Santiago Cardoso. ${ }^{51}$

En general, todos los congresos constituyentes hispanoamericanos enfrentaron el mismo problema de la soberanía en su dimensión políticoterritorial. En el caso rioplatense la Asamblea no pudo resolver el conflicto 
Sesiones de los dias 30 y 31 de enero de 1813 , Gazeta Extraordinaria Ministerial de Buenos Aires. In: RAVIGNANI, Op. cit., t. I, p. 5.

54

Al respecto, véase: FERNÁNDEZ SARASOLA, Ignacio. Los partidos políticos en el pensamiento español (1783-1855). Revista Historia Constitucional, n. 1, 2000, p. 97-163.

55

Con el fin de que la Gazeta circulara fuera de Montevideo, la salida del semanario pasó de los jueves a los martes para coincidir con la salida de los correos. SÁNCHEZ GÓMEZ, Julio. Montevideo y la Constitución de Cádiz. In: CHUST CALERO, Manuel (coord.). 1812, El poder de la palabra, América y la Constitución de 1812. Madrid: AC/E, 2012. y éste se proyectará más allá de 1815. El choque entre la vocación autonomista de las provincias del interior y el centralismo de la dirigencia porteña, con el trasfondo de los proyectos económicos y sociales que cada uno de alguna manera implicaba, marcarán el ritmo político del naciente estado-nación en las siguientes décadas.

Pero no sólo la discusión estaba planteada en términos de soberanías contrapuestas. Para la facción dirigente, la idea de proyectos alternativos, o más aun, de elementos opositores dentro del recinto, era contraria al principio de voluntad general tan característico en el primer liberalismo hispánico. La misma idea de dictar una Constitución tenía también como objetivo acabar con esa falta de unidad denunciada, como se puede observar en este artículo reproducido en El Grito del Sud:

\begin{abstract}
¿Qué será cuando la falta de constitución, deja un campo franco para dilatarse en opiniones, y querer reducir a todos al propio dictamen, aunque este no sea sino un tejido de ilusiones, o raciocinios forjados acaloradamente? La resulta, si, la resulta no es entonces otra, que la división en partido, bien pronto de estos se forman las facciones; y véase ahi la puerta abierta no solo para las disensiones que todo lo trastornan, sino que faltando la unidad, base o resorte esencialísimo de todo género de cosas, estas o se destruyen o se disuelven. En la indefinición pues de nuestro sistema han consistido todos nuestros males [...] mientras no se forme una regular constitución, no progresaremos en nuestra causa sagrada. ${ }^{52}$
\end{abstract}

En el discurso inaugural de la Asamblea General Constituyente su presidente decía:

\begin{abstract}
Cerca de tres años hemos corrido desde el principio de nuestra revolución a paso vacilante, y sobre sendas inciertas por falta de un plan que trazase distintamente las rutas de nuestra carrera y destino. Tal vez éste es el único principio que ha originado la variedad de opiniones, y la división de partidos que han debilitado considerablemente nuestra fuerza moral, que es de mayor necesidad concentrar.".53
\end{abstract}

Para éstos, una Constitución era la obra de la voluntad general que se lograba a partir del proceso discursivo en asambleas, dándose lugar al intercambio de luces donde se "descubre" aquello que es mejor para la nación. No podía existir entonces una oposición legítima, era ésta tan sólo una voluntad errada, un producto de meros intereses parciales. ${ }^{54}$

\section{Montevideo, la Constitución y la polémica en la prensa}

En la otra orilla del Río de la Plata, la leal Montevideo era una fiesta a propósito del juramento en septiembre de 1812 de la Constitución aprobada en Cádiz. El Gobernador y Capitán general Gaspar de Vigodet confiaba en que dicha Constitución sería una herramienta muy útil para contrarrestar los argumentos de la insurgencia porteña. Prácticamente desde el comienzo del movimiento juntista, el enfrentamiento entre ambas ciudades había generado un cruce de acusaciones y réplicas que en muchos casos eran canalizadas a través de la prensa. La Gazeta de Montevideo, nacida en la Banda Oriental como reacción a la difusión de su par la Gazeta de Buenos Aires, se convirtió rápidamente en un órgano de propaganda de la Regencia y las Cortes para los territorios rioplatenses. ${ }^{55}$

A poco de conocerse las noticias que llegaban de la península sobre la promulgación de la constitución gaditana, es publicado un artículo en la Gazeta de Buenos Aires rechazando su legitimidad: 
56

Gazeta Ministerial del Gobierno de Buenos Aires, $11 /$ set/1812.

57

"Oficio del Excmo. Supremo Gobierno de las Provincias Unidas del Rio de la Plata al gobierno de Montevideo", Gazeta Ministerial del Gobierno de Buenos Aires, 11/set/1812.

58

Ibidem.

Sobre la circulación de Blanco White en el Rio de la Plata, puede consultarse a PASINO, Alejandra. El Español de José María Blanco-White en la prensa porteña durante los primeros años revolucionarios. In: HERRERO, Fabián (comp.). Revolución. Política e ideas en el Río de la Plata. Buenos Aires: Ediciones Cooperativas, 2004.
Nos hablan ahora de constitución: pero esa constitución establece al dogma de la soberana nacional, reconoce por única base de su representación a la población dé las provincias, y si ella no ha existido para la América ¿tendrá ésta obligación alguna de obedecerla? Si esta constitución es justa y liberal, solamente la libre sanción de los pueblos puede legitimarla: la fuerza y la opresión jamás han producido derecho. ${ }^{56}$

En la Gazeta del mismo día, se incluye un oficio que el Triunvirato dirigió al gobierno de Montevideo, llamándolos a desistir de su oposición a la "causa americana":

V. E. sabe, cuanto es peligrosa la situación actual de la península, y difícil la reconquista de sus provincias; y ya se ve, que no estaría en los términos de la prudencia, ni en el orden de los intereses políticos de la nación, influir en la destrucción de los pueblos americanos, solamente por sostener la autoridad de un gobierno vacilante. La nación señor general no está vinculada a la Regencia. Bien pueda de esta desaparecer, y realizarse la conquista de la península siempre existirá la nación española en este hemisferio y si sus pueblos unidos reconocen un mismo Soberano, y gobernados por una constitución sabia y justa adquieren la fuerza necesaria, para resistir las miras ambiciosas de sus enemigos; pero si continua la división, su pérdida es inevitable..$^{57}$

En ese mismo número, se reproduce la contestación del Gobernador Vigodet a dicho oficio, donde reafirma su lealtad a la metrópoli, a la vez que envía varios ejemplares de la Constitución española recientemente publicada, incitando a las Provincias Unidas a jurarla:

La sabia, y benéfica constitución de la monarquía española, de que remito a V. E. seis ejemplares, le convencerán de la injusticia con que declama contra las deliberaciones del Congreso, y la regencia del reyno. Si V. E. entrase en sus deberes, y meditase sobre el origen funesto de las desdichas, que es preciso evitar para ser justos, entonces nos hallará pronto para estrechar la unión entre ambos pueblos, del mismo modo que Montevideo está unido con toda la nación: decídase V. E, a jurar la constitución de la Monarquía, y decido así la libertad o independencia de la América del Sud. ${ }^{58}$

En ocasión de esta polémica por la negativa de Buenos Aires a reconocer a las Cortes, la Gazeta montevideana acusaba a la prensa porteña de "emplear las reproducciones de El Español, de Blanco White, para desprestigiar la labor de las Cortes y fomentar la desunión entre americanos y españoles", presentando al sevillano como un "renegado vendido al oro de los ingleses". En numerosas ocasiones la prensa en Buenos Aires hubo de utilizar artículos provenientes de la pluma de Blanco White para legitimar su oposición a las Cortes y sus reclamos autonomistas. ${ }^{59}$ También es cierto que la insistencia del redactor de El Español por mantener la unidad de la Monarquía y sus continuos pedidos de moderación, fundamentalmente a partir de la declaración de independencia de Caracas, llevó a los revolucionarios porteños, entre ellos Monteagudo, a relativizar algunas de sus opiniones, adjuntar notas al pie a sus artículos marcando las diferencias y poco a poco dosificar cada vez más su publicación.

Volviendo a Montevideo, más allá de la voluntad de las autoridades, la puesta en práctica de la Constitución gaditana no fue para nada sencilla. El crítico contexto militar no sólo por el enfrentamiento con Buenos Aires, sino con la campaña ganada por el artiguismo, tuvo como consecuencia que nunca se pudieran llevar adelante las elecciones para diputados a Cortes. 
60

HALPERÍN DONGHI, Túlio. Op. Cit. El alejamiento de San Martín de la capital, abocado de lleno ya a la campaña americana, permitió la hegemonía de Alvear dentro de la elite dirigente, liderazgo que fomenta dicho estrechamiento y agudiza las contradicciones con el artiguismo.

61

GONZÁLEZ BERNALDO, Pilar. La Revolución Francesa y la emergencia de nuevas prácticas de la política: La irrupción de la sociabilidad politica en el Río de la Plata (1810-1815). Boletín del Instituto de Historia Argentina y Americana "Dr. E. Ravignani", III serie, n. 3, 1991, p. 7-27.
GOLDMAN, Noemí. Historia y lenguaje. Los discursos de la Revolución de Mayo. Buenos Aires: Centro Editor de América Latina, 1992.
Clima tormentoso para la Revolución: la Asamblea naufraga en su impotencia Desde fines del año XIII la coyuntura se fue volviendo cada vez más adversa: al seguro retorno de Fernando VII y la restauración cabalgando por toda Europa, se le suman las derrotas y desorganización en el Ejército del Norte y la expansión cada vez más pronunciada del artiguismo, atemperando los iniciales bríos de la Asamblea General Constituyente. Los ambiciosos fines de declaración de independencia y dictado de una Constitución serán reemplazados por los más moderados pero no menos acuciantes objetivos del corto plazo. La revolución debía sobrevivir. Este cambio también se puede observar en la forma en que se fue reestructurando la elite dirigente. El estrechamiento de la base del poder revolucionario con el paso de la Sociedad Patriótica, cuyos fines se centraban en el esclarecimiento ideológico, a la Logia Lautaro, cabal ejemplo de una maquinaria de dominación política monopolizada ahora por el alvearismo, muestra a las claras dicha necesidad de preservación. ${ }^{60} \mathrm{El}$ recurso a la opinión pública como medio de control y acceso al poder es abandonado, la política se restringe a un sector bien reducido, y lo que se pierde en cuanto a base social se intenta ganar en eficacia. ${ }^{61}$ Estrechamiento que se traduce también institucionalmente. Desde la creación del Directorio, el 21 de enero de 1814, la Asamblea no vuelve a reunirse cuando es convocada por éste, retornando a un largo letargo, sólo para constituirse de manera extraordinaria para designar a Alvear en reemplazo de Posadas como Director en enero de 1815.

Rastros de la cultura constitucional hispánica continuarian presentes en el Estatuto Provisorio de 1815 y en su reemplazante, el Reglamento Provisorio de 1817. Algunos de los preceptos compartidos con el doceañismo serian: la religión católica como religión del Estado, el régimen de ciudadanía, el sistema electoral, la división de poderes con supremacía legislativa, el unicameralismo y las secretarias del Estado, entre otros. Con el reglamento de 1817 culminaria la impronta peninsular en la legislación rioplatense para, desde aquí ir cediendo terreno con respecto a otras fuentes, en particular la Constitución de Filadelfia.

\section{A modo de conclusión}

A pesar de no declarar la independencia ni terminar dictando Constitución, sus objetivos principales, la labor de la Asamblea tuvo una significativa trascendencia para el proceso emancipatorio del sur del continente. Fue sin lugar a dudas el intento más serio por parte del sector más revolucionario del movimiento, de concretar las transformaciones políticas y sociales para romper de manera definitiva con el antiguo régimen $y$, en palabras de sus propios protagonistas, poner al Río de la Plata en "el camino de la libertad". La promulgación del decreto de libertad de vientres, la libertad de prensa, la extinción del tributo, la mita y la encomienda, la abolición de la inquisición y del uso de tormentos, la supresión de los títulos de nobleza y del mayorazgo, entre otras resoluciones del Congreso, son ejemplos de esta vocación de embarcar al espacio rioplatense en la marea de cambios que estaba recorriendo gran parte de Europa y América. Para los "morenistas" separarse de España o de su rey no alcanzaba, era necesario construir "una república inspirada en principios liberales e igualitarios». ${ }^{62}$

Como hemos querido demostrar, el conflicto abierto con la metrópoli no implicó que ese trasfondo político-cultural común no se expresara a través de similares políticas a ambos lados del Atlántico. En el bienio 1808-1810 la relación había sido fértil en términos doctrinarios entre los 
CHUST CALERO, Manuel. La cuestión nacional americana en las Cortes de Cádiz. 0p. cit. p. 22.

64

Gazeta Ministerial del Gobierno de Buenos Aires, 01/jan/1813.

65

TERNAVASIO, Marcela. La experiencia gaditana en el Río de la Plata: batallas retóricas y aprendizaje político. In: CHUST CALERO, Manuel (coord.). 1812, Op. Cit.
Recebido para publicação em janeiro de 2014 Aprovado em abril de 2014 promotores del cambio político tanto peninsulares como americanos. Pero esta relación comenzó a resquebrajarse ante la intransigencia de la metrópoli hacia los reclamos y aspiraciones americanas, fundamentalmente en referencia a la igualdad de representación, la descentralización política y la liberalización comercial. Las actitudes de los liberales peninsulares hacia los asuntos americanos rara vez se diferenciaban del grupo tradicionalista de las Cortes, alejándose del "radicalismo" con el que buscaban imprimir los cambios en el contexto peninsular. Aun batallando de forma conjunta con los americanos en muchos de los puntos del programa liberal, la diputación peninsular buscó en reiteradas ocasiones postergar las exigencias y propuestas de aquellos. Retomando a Manuel Chust, la diputación ultramarina «insistirá en su afán de integrar todo un imperio en calidad de provincias iguales en el preciso momento de la construcción del estado nacional.» Pero, como éste se pregunta, "¿era posible estructurar una monarquía constitucional bajo parámetros federales?» La historia no registraba antecedentes. ${ }^{63}$ Sin embargo, a esta altura, las propuestas federalistas no eran la única opción planteada en el continente americano: la dinámica del conflicto entre la península y los territorios insurgentes había llevado a estos últimos a radicalizar sus posiciones hacia planteos que tenian a la independencia total como horizonte cada vez más cercano. La promulgación de la Constitución española vino a profundizar esta brecha entre la insurgencia rioplatense y la Península. La dirigencia porteña consideró entonces que las Cortes habian clausurado de esa manera cualquier posibilidad de negociación:

Las Cortes han declarado a la faz del mundo que no quieren conciliación con las provincias de América que se hallan en revolución. Desechando la conciliación han declarado implícitamente que es su voluntad, que las armas decidan la cuestión presente, que si los americanos son vencidos se han de someter por derecho de conquista a las leyes que las Cortes le han dado. ${ }^{64}$

Aun así la Constitución de Cádiz sirvió como fuente, como hemos demostrado, para las legislaciones y proyectos constitucionales que estuvieron en discusión en los primeros años de camino propio de las Provincias Unidas del Rio de la Plata. Como plantea Ternavasio, ésta puso a su disposición una gramática jurídica que presentaba importantes ventajas para ser asimilada y adaptada por las élites americanas. ${ }^{65}$ Pero poco a poco comenzó a ser remplazada por otras fuentes que fueron ganando terreno a medida que la ruptura total con la "Madre Patria" iba confirmándose.

Existió un lenguaje y una práctica política común a ambos lados del Atlántico, aunque en ocasiones, producto de las dinámicas particulares de cada proceso, adquirieran significaciones y usos divergentes. Las condiciones coyunturales y las necesidades políticas en muchos casos terminaban determinando las posiciones que adoptaron los actores políticos aun cuando en algunos casos contradijeran algunas de sus proclamadas convicciones doctrinarias. En el marco de una misma cultura constitucional hispánica, que se consolidó entre 1808 y 1824, la labor legislativa de las Cortes y fundamentalmente la Constitución doceañista pusieron a disposición de los rioplatenses un nuevo lenguaje constitucional que representó, por un lado, la posibilidad de dotarse de útiles herramientas político-jurídicas para promover los cambios que ambicionaban, pero que a su vez generó fuertes tensiones y contradicciones, en pleno proceso de emancipación de las antiguas colonias americanas. 